\title{
Epidemiological and Clinical Aspects of Congenital Hydrocephalus in the Neonatal Department of Gabriel Touré Teaching Hospital Bamako Mali
}

\author{
Hawa G. Diall1 ${ }^{*}$, Oumar Coulibaly ${ }^{1}$, Youssouf Sogoba², Hatouma Sylla1, Yacouba A. Coulibaly¹, \\ Fatoumata L. Diakité1, Lala N. Sidibé1, Ibrahima Ahamadou', Leyla Maiga1, Abdoul K. Doumbia1, \\ Pierre Togo1, Adama Dembélé1, Mohamed E. Cissé1, Fousseini Traoré1, Belco Maiga1, \\ Karamoko Sacko', Djeneba Konaté1, Bourama Kané3 ,Oumou Koné4, Guedjouma Dembélé ${ }^{3}$, \\ Abdoul A. Diakité1, Drissa Kanikomo², Fatoumata D. Traoré1, Mariam Sylla1, Boubacar Togo ${ }^{1}$
}

${ }^{1}$ Department of Pediatrics, CHU Gabriel Touré, Bamako, Mali

${ }^{2}$ Department of Neurosurgery, CHU Gabriel Touré, Bamako, Mali

${ }^{3}$ Department of Pediatrics, Hospital Mali, Bamako, Mali

${ }^{4}$ National Institute of Public Health, Bamako, Mali

Email: ^diallhawa@gmail.com

How to cite this paper: Diall, H.G., Coulibaly, O., Sogoba, Y., Sylla, H., Coulibaly, Y.A., Diakité, F.L., Sidibé, L.N., Ahamadou, I., Maiga, L., Doumbia, A.K., Togo, P., Dembélé, A., Cissé, M.E., Traoré, F., Maiga, B., Sacko, K., Konaté, D., Kané, B., Koné, O., Dembélé, G., Diakité, A.A., Kanikomo, D., Traoré, F.D., Sylla, M. and Togo, B. (2022) Epidemiological and Clinical Aspects of Congenital Hydrocephalus in the Neonatal Department of Gabriel Touré Teaching Hospital Bamako Mali. Open Journal of Pediatrics, 12, 1-11.

https://doi.org/10.4236/ojped.2022.121001

Received: November 25, 2021

Accepted: January 4, 2022

Published: January 7, 2022

Copyright $\odot 2022$ by author(s) and Scientific Research Publishing Inc. This work is licensed under the Creative Commons Attribution International License (CC BY 4.0). http://creativecommons.org/licenses/by/4.0/

\begin{abstract}
Objective: The aim of our work was to access the epidemiological and clinical aspects of congenital hydrocephalus in the pediatrics department of Gabriel Touré teaching Hospital Bamako. Methods: We conducted a retro and prospective study that ran from January, 1st 2018 to July, 30, 2019. All newborns of 72 hours of life or less with hydrocephalus confirmed by sonography or CT scan were enrolled in this study. Results: During the study period, 5416 patients were hospitalized in the neonatology department. Among them, 39 patients $(0.72 \%)$ presented congenital hydrocephalus and congenital infectious causes accounted for $25.6 \%$. The sex ratio (M/F) was 1.78 . Mothers were housewives and not educated in $79.5 \%$ and $64.1 \%$ respectively. The parents resided outside Bamako in $61.5 \%$ of cases. Prenatal consultations were conducted in 32 patients (82\%). Consanguinity between the 2 parents was present in $38.5 \%$. The antenatal diagnosis was made in 8 patients $(20.5 \%)$. Vaginal delivery was the main mode of birth (67\%). The average birth weight was 2930 $\mathrm{g}(1000$ to $5400 \mathrm{~g})$ and the average head circumference was $37.82 \mathrm{~cm}(26-55$ $\mathrm{cm})$. In $87.2 \%$ of cases, newborns were eutrophic. The main clinical signs were bulging anterior fontanel $(46.2 \%)$, sunset gaze $(20.5 \%)$, prominent forehead $(48.7 \%)$, reduced face $(20.5 \%)$, enlarged cranial sutures $(43.6 \%)$, macrocrania (25.6\%). Transfontanellar ultrasound and CT scan were performed in $51.3 \%$
\end{abstract}


and $48.7 \%$ of cases respectively. Associated malformations were spina bifida in $30.8 \%$ of cases followed by Dandy Walker malformation (5.1\%), and omphalocele $(2.5 \%)$. The neurological signs were diminished neonatal reflexes (51.3\%), hypotonia (30.8\%), motor deficit (38.4\%), intracranial hypertension (25.6\%), seizures $10.25 \%$ and psychomotor delay (43.6\%). Surgery was performed in 8 neonates (20.5\%). Ventriculo-peritoneal shunt (VPB) was the main treatment. Postoperative complications were infectious (37.5\%) and mechanical complications (12.5\%). The postoperative mortality rate was $12.5 \%$.The overall mortality was 13 cases $(33.3 \%)$. Conclusion: The hospital frequency of congenital hydrocephalus in our environment seems low but does not reflect reality.

\section{Keywords}

Newborn, Congenital Hydrocephalus, Mortality, Gabriel Toure

\section{Introduction}

Hydrocephalus that occurs in early childhood, with no obvious extrinsic causal event, is commonly referred to as congenital hydrocephalus $(\mathrm{CH})$ and is generally present at birth. [1]. It is an important factor of morbidity and mortality in developing countries with limited diagnostic and therapeutic means [2]. Hydrocephalus often requires surgery and lifelong treatment with multidisciplinary team [3]. The main characteristics are the accumulation of cerebrospinal fluid (CSF) in the ventricular space with consequently ventricular dilatation [4]. Prematurity, infection (embryofoetopathy) and intracranial structural abnormalities such as neural tube abnormalities (NTD) and aqueduct stenosis may result in congenital hydrocephalus [5] [6]. Its prevalence and incidence in many sub-Saharan African countries, including Mali, are unknown. According to Dewan et al. (2018), the incidence of congenital hydrocephalus is 79 to 123 per 100,000 births in low- and middle-income countries [7]. In these countries antenatal diagnosis is not systematic [8] [9] and management is most often delayed due to undermedicalization, poverty, sociocultural beliefs and taboos that surround this pathology [2]. Among the risks mentioned in the genesis of hydrocephalus, we find: consanguineous marriage which multiplies by 13 the risk of developing hydrocephalus [10], non-supplementation with iron-folic acid during pregnancy, self-medication and the use of traditional medicines [11].

Despite progress in the management of hydrocephalus in children, mortality from this condition remains high [12] and long-term sequelae can be disabling.

In Bamako, Mali, in the neonatal department of the Gabriel Touré University Hospital, hydrocephalus accounts for $5.3 \%$ of the whole surgical congenital malformations [13]. The neonatology and neurosurgery departments, provide synergistic care for congenital hydrocephalus conditions. Until then, no study had examined the problem of congenital hydrocephalus of the newborn admitted to the neonatology department. The aim of the study was to access epidemi- 
ological and clinical characteristics of newborns hospitalized for congenital hydrocephalus.

\section{Patients and Method}

We conducted a 19-month retrospective and prospective study from (January, $1^{\text {st }}$ 2018 to July, 30, 2019) in the neonatology service... It provides care to newborn referred from the city of Bamako and its neighboring areas. The service receives all neonatal emergencies including surgical and neurosurgical ones.

The management of newborns with congenital hydrocephalus is multidisciplinary. Surgical management is provided by neurosurgeons and pre- and postoperative surgery by neonatologists. All neonates from 0 to 72 hours of live hospitalized for hydrocephalus were included. Newborns older than 72 hours and for other pathologies have not been included.

The retrospective part of the study covered 12 months (January $1^{\text {st }}$ to December, 30,2018 ) and the prospective part covered 9 months (January $1^{\text {st }}$ to July 30 , 2019).

Data were collected from mothers and/or caregivers and the neonatal medical record. The parameters studied were epidemiological, clinical, paraclinical, therapeutic and prognostic aspects. The data were collected on a standardized Survey form. The analysis was performed using the following software: Word 2016 and SPSS version 25 .

\section{Results}

During the study period, 5416 patients were hospitalized in the neonatology department. Among them, 39 patients $(0.72 \%)$ presented congenital hydrocephalus. Sex ratio was 1.78. Mothers were housewives and not educated in $79.5 \%$ and $64.1 \%$ respectively. The Parents resided outside Bamako (61.5\%). Prenatal consultations were conducted in 32 patients (82\%). Consanguinity rate between the 2 parents was (38.5\%). The antenatal diagnosis was made in 8 patients $(20.5 \%)$. Vaginal delivery was the main mode of delivery $(67 \%)$. The average birth weight was $2930 \mathrm{~g}$ (1000 to $5400 \mathrm{~g}$ ) and the average head circumference was $37.82 \mathrm{~cm}$ (26 to $55 \mathrm{~cm}$ ). In $87.2 \%$ of cases, newborns were eutrophic. The main socio-demographic characteristics, pre and per-natal antecedents are summarized in Table 1.

The main clinical signs were prominent forehead (48.7\%), bulging anterior fontanel (46.2\%), enlarged cranial sutures (43.6\%), macrocrania (25.6\%). sunset gaze $(20.5 \%)$, reduced face $(20.5 \%)$. The main clinical signs found are summarized in Table 2. The neurological signs were diminished neonatal reflexes (51.3\%), hypotonia (30.8\%), motor deficit (38.4\%), intracranial hypertension (25.6\%), seizures $10.25 \%$ and psychomotor delay (43.6\%). The main neurological signs found are summarized in Table 3.

Transfontanellar ultrasound and CT scan were performed in 51.3\% and 48.7\% of cases respectively. Associated malformations accounted for $38.4 \%$ of cases. 
Table 1. Socio-demographic characteristics and pre-and per-natal antecedents.

\begin{tabular}{|c|c|c|}
\hline Variable & Frequency $(n=39)$ & Percent \\
\hline \multicolumn{3}{|l|}{ education level } \\
\hline not educated & 25 & 64.1 \\
\hline educated & 14 & 35.9 \\
\hline \multicolumn{3}{|l|}{ occupation } \\
\hline Housewife & 31 & 79.5 \\
\hline others & 8 & 20.5 \\
\hline \multicolumn{3}{|l|}{ consanguinity } \\
\hline Yes & 15 & 38.5 \\
\hline No & 25 & 64.1 \\
\hline \multicolumn{3}{|l|}{ Résidence } \\
\hline Bamako & 15 & 38.5 \\
\hline Outside Bamako & 24 & 61.5 \\
\hline \multicolumn{3}{|c|}{ Prenatal consultations } \\
\hline Yes & 32 & 82 \\
\hline No & 7 & 18 \\
\hline \multicolumn{3}{|l|}{ Prenatal diagnosis } \\
\hline Yes & 8 & 20.5 \\
\hline No & 31 & 79.5 \\
\hline \multicolumn{3}{|l|}{ Delivery route } \\
\hline Vaginal & 26 & 67 \\
\hline Caesarean section & 13 & 33 \\
\hline \multicolumn{3}{|l|}{ Birth weight } \\
\hline Eutrophic & 34 & 87.2 \\
\hline Hypotrophe & 5 & 12.8 \\
\hline \multicolumn{3}{|l|}{ Sex } \\
\hline Male & 25 & 64 \\
\hline Female & 14 & 36 \\
\hline
\end{tabular}

Table 2. Main clinical signs

\begin{tabular}{ccc}
\hline Variable & Frequency $(\mathbf{n}=\mathbf{3 9})$ & Percent \\
\hline Prominent fore head & 19 & 48.7 \\
Bulging anterior fontanel & 18 & 46.2 \\
Enlarged cranial sutures & 17 & 43.6 \\
Macrocrania & 9 & 25.6 \\
Sunset gaze & 8 & 20.5 \\
Reduced face & 8 & 20.5 \\
\hline
\end{tabular}


These were mainly spina bifida (30.8\%), Dandy Walker malformation (5.1\%), and omphalocele (2.5\%). Congenital infectious causes accounted for $25.6 \%$. The main étiologies found are summarized in Table 4.

Surgery was performed in 8 neonates (20.5\%).Ventriculo-peritoneal shunt (VPB) was the main treatment. The intervention was made in less than 5 days in 4 newborns or $50 \%$ of cases operated. Postoperative complications were infectious $(37.5 \%)$ and mechanical (12.5\%).The postoperative mortality was 1 case $12.5 \%$.The overall mortality was 13 cases $(33.3 \%)$. The characteristics of operated newborns are summarized in Table 5.

The different causes of death were: metabolic disorders (30.7\%), meningitis (15.4\%), and respiratory distress syndrome (hyaline membrane disease):7.7\%. The other causes were unknown $(46.2 \%)$. The outcome of the newborns is summarized in Table 6.

Table 3. Main Neurological signs.

\begin{tabular}{ccc}
\hline Variable & Frequency $(\mathbf{n}=\mathbf{3 9})$ & Percent \\
\hline diminished neonatal reflexes & 20 & 51.3 \\
Hypotonia & 12 & 30.8 \\
motor deficit & 15 & 38.4 \\
Intracranial hypertension & 10 & 25.6 \\
seizures & 4 & 10.25 \\
psychomotor delay & 17 & 43.6 \\
\hline
\end{tabular}

Table 4. The main etiologies.

\begin{tabular}{ccc}
\hline Variable & Frequency $(\mathbf{n}=\mathbf{3 9})$ & Percent \\
\hline Malformations & & \\
Spina bifida & 12 & 30.8 \\
Dandy -Walker & 2 & 5.1 \\
Omphalocele & 1 & 2,5 \\
Congenital infectious causes & 10 & 25.6 \\
unknown causes & 14 & 35.9 \\
\hline
\end{tabular}

Table 5. Characteristics of operated newborns.

\begin{tabular}{ccc}
\hline Variable & Frequency $(\mathrm{n}=8)$ & Percent \\
\hline Sex & 5 & \\
Male & 3 & 62.5 \\
Female & & 37.5 \\
Time intervention (days) & 4 & \\
$<5$ & & 50.0 \\
\hline
\end{tabular}


Continued

\begin{tabular}{ccc}
\hline $5-10]$ & 3 & 37.5 \\
$>10$ & 1 & 12.5 \\
Postoperative follow-up & & \\
Favorable & 4 & 50.0 \\
Infection & 3 & 37.5 \\
Catheter migration & 1 & 12.5 \\
outcome & & \\
Exeat & 7 & 87.5 \\
Death & 1 & 12.5
\end{tabular}

Table 6. The causes of death.

\begin{tabular}{ccc}
\hline The causes of death & Frequency $(\mathbf{n}=13)$ & Percent \\
\hline Metabolic disorders & 4 & 30.7 \\
Meningitis & 2 & 15.4 \\
Hyaline membrane disease & 1 & 7.7 \\
unknown causes & 6 & 46.2 \\
\hline
\end{tabular}

\section{Discussion}

Our study included all neonates from 0 to 72 hours of live hospitalized for congenital hydrocephalus in the neonatal department during the study period. The frequency of congenital hydrocephalus in the department was $0.72 \%$. This frequency probably does not reflect in the true situation. The frequency of hydrocephalus varies from study to study, Kamla from Cameroon [12] and Mouafo [14] found $12.69 \%$ and $55.5 \%$ respectively. Barry reported $22.46 \%$ in Guinea [15], Wilson found 12.3\% in Morocco [16] and Junior 43.3\% in Democratic Republic of Congo (DRC) [17].

In our study, male newborns were the most affected with a sex ratio $(\mathrm{M} / \mathrm{F})$ of 1.78. This predominance was also found in the Barry's study [15] and Tapsoba [18]. By contrast, in the Salem-Memou series [19] in Mauritania, the female sex was predominant. The predominance of the male sex was reported by several studies. It is partly explained by the fact that congenital hydrocephalus can be transmitted in a recessive mode linked to the sex [20].

The role of inbreeding is well established in the occurrence of central nervous system malformations in general and congenital hydrocephalus in particular [21]. In our study, the notion of inbreeding was found in $38.50 \%$. This inbreeding varies from one country to another with $77 \%$ in Guinea [15], 48.7\% in Morocco [21] and 7.9\% in Mauritania [19].

Antenatal diagnosis remains a handicap in developing countries. In our study, it could be performed in 8 newborns (20.5\%). In some studies, such as Ndour O 
[8] and Salem-Memou [19], no antenatal diagnosis has been made.The prevalence of antenatal diagnosis of hydrocephalus remains low, this is mainly due to the low rate of well-followed pregnancies in our context. In our series, pregnancies were followed in $82 \%$ of cases.

The average birth weight was $2930 \mathrm{~g}(1000-5400 \mathrm{~g})$ and the average head circumference was $37.82 \mathrm{~cm}(26-55 \mathrm{~cm})$. In $87.2 \%$ of cases, newborns were eutrophic. Premature infants are at risk of presenting intraventricular hemorrhage followed by post-hemorrhagic hydrocephalus ( $\mathrm{HPH})$. In our study they represented (5) cases (12.8\%).Intraventricular hemorrhage is the most important adverse neurologic event for preterm and very low weight birth infants in the neonatal period. This pathology can lead to various delays in motor, language, and cognition development [22].

The main clinical signs in our study were prominent fore head (48.7\%), bulging anterior fontanel (46.2\%), enlarged cranial sutures (43.6\%), sunset gaze (20.5\%), reduced face $(20.5 \%)$. Macrocrania is the first sign that most often directs parents or health workers. In our series, it represented $25.6 \%$ of cases, most often a symptom indicative of hydrocephalus, this remains in accordance with the data in the literature [21] [23]. Sunset gaze was recorded in $20.5 \%$ of our patients, Tapsoba [18] reported 66\%. In our series the neurological signs were diminished neonatal reflexes (51.3\%), hypotonia (30.8\%), motor deficit (38.4\%), intracranial hypertension (25.6\%), seizures $(10.25 \%)$ and psychomotor delay (43.6\%). Tabarki et al., [11] Tapsoba et al., [18] found 23.25\% and 15\% of psychomotor delay, 5.81\% respectively. In Mauritania Salem-Memou et al. [19] reported $35.7 \%$ of psychomotor delay, hypotonia $7.6 \%$.

Although the methods of choice for the study of hydrocephalus are MRI and CT scan [24] [25], transfontanellar ultrasound plays an important role in the diagnosis and characterization of brain damage in newborn. It is considered to be a method of choice for the evaluation of the newborn at risk, being, in most cases, the only method necessary [25]. In our study, it could be performed in 20 newborns (51.3\%), a higher rate than that found by Salem-Memou in Mauritania [19]. The CT scan is the gold standard to affirm the ventricular dilation, its topography and to suspect the etiology. It also makes possible to follow the outcome of hydrocephalus. It was performed in our study in 19 patients (48.7\%), in Mauritania (84.1\%) [19]. Triventricular hydrocephalus was the most frequent type in our series (53.9\%), Adjenou al. reported 41.82\% triventricular hydrocephalus [23].

Congenital infectious causes of hydrocephalus are predominant in hydrocephalus etiologies in sub-Saharan Africa. In our study, the infectious causes accounted for $25.6 \%$ of cases. The study carried out in Burkina Faso by Tapsoba et al. [18] found infectious causes in $43.4 \%$ of cases. Work carried out in other countries, notably in Benin [26] and Senegal [27] found similar results with an infectious predominance in $80.7 \%$ (10) and $46 \%$ (2) respectively.

In our study, associated malformations accounted for $38.4 \%$ of cases. These were mainly spina bifida (30.8\%), Dandy Walker malformation (5.1\%), and om- 
phalocele (2.5\%). Adjenou [23] and Tabarki [11], reported 5.45\% cases of Dandy-Walker malformation and 25.7\%. In the study conducted by Salem-Memou et al. spina bifida represented (23.8\%), Dandy-Walker malformation (13.4\%) [19]. junior et al., reported 56.5\%) of spina bifida in the DRC [17]. In the present study, mothers were housewives and not educated in $79.5 \%$ and $64.1 \%$ respectively. The low level of education of mothers of children with congenital hydrocephalus increases communication difficulties for a preventive strategy. This prevention is important because abnormalities of the central nervous system are frequent and, above all, responsible for a large part of neonatal mortality and morbidity [12]. If the occurrence of these malformations is of multifactorial origin (genetic, environmental...), it is however established that it is correlated with low intakes of folic acid or vitamin B9. A better access of childbearing women to prenatal supplementation with folic acid s may further reduce the frequency of this pathology with serious neurological sequelae [19].

Hydrocephalus is a health problem in developing countries, mainly in subSaharan Africa where $90 \%$ of affected children would not be treated [28] [29]. It is a serious condition, which can compromise the vital or functional prognosis in the lake of correct and early management. Ventriculo-peritoneal shunt (VPB) remains the treatment of choice for hydrocephalus. In our study, it was carried out in patients (20.5\%) in Mauritania (68.8\%) [19]. All our patients could not benefit from surgery. This could be explained by the poor access to health services, the late diagnosis of the disease, the lack of insurance coverage and the poverty of the population.

In our study, the main postoperative complications were infectious (37.5\%) and mechanical (12.5\%). In the series by Hugues et al., infection was present in 21 out of 60 patients [30], Salem Memou et al., reported (15.8\%) infectious complications and 7.8\% mechanical complications [19]. In developed countries, infectious complications are less common. In fact, in the series by Torstein R [31], in Norway the complications were infectious in $6.2 \%$ of cases and mechanical in $46.8 \%$ of cases.

The postoperative mortality was 1 case $(12.5 \%)$.The overall mortality was $33.3 \%$ (13 cases) in our study. A high mortality rate was also observed in Benin $46.6 \%$ [30]. In Mauritania the overall mortality was $4.7 \%$ [19]. These high mortality rates are justified by the newborn fragility, the diagnosis that is not made during the prenatal period, the lack of an adequate intensive care units, the diagnosis delay the supply of drugs which is left to the sole responsibility of the parents and the poor evacuation conditions of these newborns.

The main limitations of our study were related to his retrospective aspect and the problem of archiving clinical records, which did not allow us to collect all the information concerning the antenatal, per- and post-natal histories of our patients.

\section{Conclusion}

The hospital frequency of congenital hydrocephalus in our environment seems 
low but does not reflect reality. This is a serious condition that can compromise the vital or functional prognosis in the absence of correct and early treatment. Despite the efforts made in the field of neurosurgical equipment and the training of neurosurgeons, much remains to be done. Emphasis should be placed on the prevention of neural tube defects by prenatal folic acid supplementation which may reduce the frequency of this pathology with serious neurological sequelae.

\section{Conflicts of Interest}

The authors declare no conflicts of interest regarding the publication of this paper.

\section{References}

[1] Tully, H.M., Capote, R.T. and Saltzman, B.Y. (2015) Maternal and Infant Factors Associated with Infancy-Onset Hydrocephalus in Washington State. Pediatric Neurology, 52, 320-325. https://doi.org/10.1016/j.pediatrneurol.2014.10.030

[2] Muir, R.T., Wang, S. and Warf, B.C. (2016) Global Surgery for Pediatric Hydrocephalus in the Developing World: A Review of the History, Challenges, and Future Directions. Neurosurgical Focus, 41, E11. https://doi.org/10.3171/2016.7.FOCUS16273

[3] Munch, T.N., Rasmussen, M.H., Wohlfahrt, J., et al. (2014) Risk Factors for Congenital Hydrocephalus: A Nationwide, Register-Based, Cohort Study. Journal of Neurology, Neurosurgery and Psychiatry, 85, 1253-1259. https://doi.org/10.1136/jnnp-2013-306941

[4] McAllister, J.P. (2012) Pathophysiology of Congenital and Neonatal Hydrocephalus. Seminars in Fetal and Neonatal Medicine, 17, 285-294.

https://doi.org/10.1016/j.siny.2012.06.004

[5] Zhang, J., Williams, M.A. and Rigamonti, D. (2006) Genetics of Human Hydrocephalus. Journal of Neurology, 253, 1255-1266. https://doi.org/10.1007/s00415-006-0245-5

[6] Mataro, M., Junque, C., Poca, M.A. and Sahuquillo, J. (2001) Neuropsychological Findings in Congenital and Acquired Childhood Hydrocephalus. Neuropsychology Review, 11, 169-178. https://doi.org/10.1023/A:1012904907249

[7] Dewan, M.C., Rattani, A., Mekary, R., Glancz, L.J., Yunusa, I., Baticulon, R.E., et al. (2019) Global Hydrocephalus Epidemiology and Incidence: Systematic Review and Meta-Analysis. Journal of Neurosurgery, 130, 1065-1079.

[8] Ndour, O., Faye, F.A., Alumeti, D., Gueye, K., Amadou, I., et al. (2009) Risk Factors for Neonatal Mortality Factors at the Paediatric Surgeon Service in Aristide Le Dantec University Hospital in Dakar. Mali Médical, 24, 33-38.

[9] Ralahy, M.F., Rakotoarivony, S.T., Rakotovao, M.A., Hunald, F.A., Rabenasolo, M., et al. (2010) The Neonatal Mortality in the Emergency Unit of the JRA University Teaching Hospital in Antananarivo Madagascar. Revue d Anesthésie-Réanimation et de Médecine d' Urgence, 2, 15-17.

[10] Kalyvas, A.V., Kalamatianos, T., et al. (2016) Maternal Environmental Risk Factors for Congenital Hydrocephalus: A Systematic Review. Neurosurgical Focus, 41, E3. https://doi.org/10.3171/2016.8.FOCUS16280

[11] Tabarki, B. (2001) Hydrocéphalies de l'enfant, aspects étiologiques et évolutifs. A propos de 86 observations. Rev Magreb Pédiatrie Mars, XI-II, 65-70. 
[12] Kamla, J.I., Kamgaing, N., Fongang, E.N., et al. (2017) Epidémiologie des Malformations Congénitales Visibles à la Naissance à Yaoundé. Health Sciences and Diseases, 18, 53-62.

[13] Dicko-Traoré, F., Diall, H., Koné, I., Samaké, B., Coulibaly, O., Amadou, I., Diakité, F.L., Ahmadou, I., Leyla, M., Diallo, S., Diallo, O., NZonou, E., Bocoum, A., Diallo, A., Diakité, A.A., Coulibaly, Y., Togo, A.P. and Sylla, M. (2019) Neonatal Surgical Emergencies in Gabriel Touré Teaching Hospital in Bamako: Epidemiological and Clinical Aspects. Pediatrics \& Neonatal Biology Open Access, 4, Article ID: 000133. https://doi.org/10.23880/PNBOA-16000133

[14] Mouafo, F.F., Djientchen, V., Chiabi, A., Mbarnjuk, S.A., Walburga, Y.J., et al. (2011) Our Experience in Management of Infantile Hydrocephalus: A Study on Thirty-Five Regrouped Cases in Yaoundé, Cameroun. African Journal of Paediatric Surgery, 8, 199-202. https://doi.org/10.4103/0189-6725.86062

[15] Barry, A., Bangoura M’mah, A., Camara, S.H., Diop, M.M., Cherif, M.S., Kouyaté, M. and Souare, I.S. (2021) Profil Sociodémographique et Clinique des Patients Suivis pour Hydrocéphalie Congénitale à l'Hôpital de l'Amitié Sino Guinéenne. Health Sciences and Disease, 22, 39-42. http://www.hsd-fmsb.org/index.php/hsd

[16] Wilson, R.D., Davies, G., Désilets, V., et al. (2003) The Use of Folic Acid for the Prevention of Neural Tube Defects and Other Congenital Abnormalities. Journal of Obstetrics and Gynaecology Canada, 25, 959-965. https://doi.org/10.1016/S1701-2163(16)30248-1

[17] Ibrahimu, J.T., Beltchika, A.K., Bianda, J.N. and Ntsambi, G.E. (2018) Aspects épidémiologiques, cliniques et thérapeutiques de l'hydrocéphalie aux Cliniques Universitaires de Kinshasa. Annales Africaines de Medecine, 12, e3086-e3092.

[18] Tapsoba, T.L., Sanon, H., Soubeiga, K.J. and Ouattara, T.F. (2010) Epidemiologic, Clinical and CT, Aspects Hydrocephalus among Children from 0 to 15 Years (Apropos of 53 Patients Colligated at the University Hospital Yalgado Ouedraogo). Médecine Nucléaire, 34, e3-e7. https://doi.org/10.1016/j.mednuc.2010.07.004

[19] Salem-Memou, S., Chavey, S., Elmoustapha, H., Mamoune, A., Ahmedou, M., Salihy, S. and Boukhrissi, N. (2020) Hydrocéphalie du nouveau-né et du nourrisson au Centre Hospitalier National de Nouakchott. Pan African Medical Journal, 36, Article No. 184.

[20] Schrander-Stummpel, C.T.R.M. and Vos, Y.J. (2004) From Gene to Disease; Xlinked Hydrocephalus and LiCAM. Nederlands Tijdschrift voor Geneeskunde, 148, 1441 1443.

[21] Sabiri, N., Kabiri, M., Razine, R., et al. (2013) Congenital Malformations Risk Factors: Prospective Study of Rabat Souissi Maternity in Morocco. Journal de Pédiatrie et de Puériculture, 26, 198-203. https://doi.org/10.1016/j.jpp.2013.05.001

[22] Valdez Sandoval, P., Hernández Rosales, P., Quiñones Hernández, D.G., Chavana Naranjo, E.A. and García Navarro, V. (2019) Intraventricular Hemorrhage and Posthemorrhagic Hydrocephalus in Preterm Infants: Diagnosis, Classification, and Treatment Options. Child s Nervous System, 35, 917-927. https://doi.org/10.1007/s00381-019-04127-x

[23] Komlanvi, A., et al. (2012) ETF et TDM dans le diagnostic des hydrocéphalies chez l'enfant à LOME. Journal de la Recherche Scientifique de PUniversité de Lomé, Série $D, 14,39-45$.

[24] Pomschar, A., Koerte, I., Peraud, A., Heinen, F., Herber-Jonat, S., Reiser, M., et al. (2012) Hydrocephalus in Childhood: Causes and Imaging Patterns. Der Radiologie, 52, 813-820. https://doi.org/10.1007/s00117-012-2334-Z 
[25] de Paul Djientcheu, V., Nguefack, S., Mouafo, T.O., Mbarnjuk, A.S., Yamgoue, T.Y., Bello, F., et al. (2011) Hydrocephalus in Toddlers: The Place of Shunts in Sub-Sahara African Countries. Child s Nervous System, 27, 2097-2100.

https://doi.org/10.1007/s00381-011-1548-0

[26] Fatigba, O.H., Noudamadjo, A., Allode, S.A. and Ayivi, B. (2011) Facteurs étiologiques et pronostiques de l'hydrocéphalie non tumorale de l'enfant au Centre Hospitalier Départemental du Borgou (Bénin). Revue du CAMES Série A, 12, 18-21.

[27] Ba, M.C., Kpelao, E.S., Thioub, M., Kouara, M., Thiam, A.B., Ndoye, N., Sakho, Y. and Badiane, S.B. (2012) Hydrocéphalie post-méningitidique du nourrisson à Dakar. African Journal of Neurological Sciences, 31, 8-14.

[28] Warf, B.C. (2010) Pediatric Hydrocephalus in East Africa: Prevalence, Causes, Treatments, and Strategies for the Future. World Neurosurgery, 73, 296-300.

https://doi.org/10.1016/j.wneu.2010.02.009

[29] Salvador, F.S., Henriques, J.C., Munguambe, M., Rui Vaz, M.C. and Henrique, B.P. (2014) Hydrocephalus in Children Less than 1 Year of Age in Northern Mozambique. Surgical Neurology International, 5, 175.

[30] Gandaho, H.J.T., Hounton, S., Kelani, A., Darga, C., et al. (2017) Impact socioéconomique et familial du traitement de l'hydrocéphalie au bénin. Santé Publique, 29, 271-278.

[31] Meling, T.R., Egge, A. and Due-Tonnessen, B. (2005) The Gravity-Assisted PaediGav Valve in the Treatment of Pediatric Hydrocephalus. Pediatric Neurosurgery, 41, 8-14. https://doi.org/10.1159/000084859 